\title{
Identity-centrality, dimensions of uncertainty, and pursuit of subgroup autonomy: The case of Sardinia within Italy
}

\author{
Joseph A. Wagoner ${ }^{1}$ (D) | Matteo Antonini ${ }^{2}$ | Michael A. Hogg ${ }^{1}$ | \\ Barbara Barbieri $^{3}$ | Alessandra Talamo²
}

\author{
${ }^{1}$ Claremont Graduate University \\ ${ }^{2}$ Sapienza Università di Roma \\ ${ }^{3}$ University of Cagliari \\ Correspondence \\ Joseph A. Wagoner, Department of \\ Psychology, Claremont Graduate University, \\ 123 East Eighth Street, Claremont, CA 91711. \\ Email: joseph.wagoner@cgu.edu
}

\begin{abstract}
Although group-related uncertainties have been shown to drive subgroups' pursuit of autonomy, it is unclear whether all group-related uncertainties motivate subgroup autonomy. We hypothesized that social identity-uncertainty, not politico-economic uncertainty, about one's subgroup is a key driver of support for subgroup autonomy. We measured Sardinian participants' ( $N=174$ ) relative subgroup (Sardinian) and superordinate group (Italian) identity-centrality, identity-uncertainty, and politico-economic uncertainty to predict support for subgroup autonomy and superordinate group fragmentation. Results showed that subgroup identity-uncertainty, not politico-economic uncertainty, elicited stronger support for subgroup autonomy, especially among highly identified subgroup members. Superordinate group fragmentation was predicted by relatively weaker superordinate identity-centrality. Results suggest that subgroups' pursuit of autonomy is driven by the hopes of reducing identity-uncertainty.
\end{abstract}

\section{1 | INTRODUCTION}

Almost all groups are hierarchically structured such that numerically smaller collectives (subgroups) are nested within numerically larger collectives (superordinate groups). For example, there are 28 nations within the European Union, 50 states within the United States, 20 regions within Italy, and so forth. In these nested category situations, a specific individual's social identity is to varying degree defined and prescribed by both their subgroup and the superordinate group within which the subgroup is nested-a French citizen is both French and European, as a resident of Sardinia is both Sardinian and Italian.

Not surprisingly, these nested subgroups experience tension with their overarching superordinate group over the degree of autonomy and control that the subgroup has over its practices and identity within the superordinate entity. The key questions, which are the focus of the present research, are what psychologically motivate the pursuit of greater subgroup autonomy within a superordinate group. Is autonomy all about social identity and associated cultural practices, or is it also about political and economic opportunity? And what are the consequences of this desire for subgroup autonomy for the superordinate group and for superordinate-subgroup relations?

Drawing on uncertainty-identity theory (Hogg, 2007, 2012 ), we propose that uncertainty about one's social identity (identityuncertainty) is perhaps a more powerful underlying motivation for the pursuit of subgroup autonomy than concerns about economic or political self-determination (politico-economic uncertainty)-even if the surface narrative appears to be about the latter. For example, the 2016 Brexit narrative in the UK often hinged on immigration and jobs, payments to the EU, and voice in Brussels; however, perhaps it was largely about preserving a distinct British identity that some felt had been eroded and had an uncertain future. Likewise, Catalonia's desire for independence from the Spanish government is not purely a pursuit of economic freedom, but also a desire for independence over their social and cultural practices. The research reported in the present article examines the extent to which the pursuit of autonomy is driven primarily by uncertainty about a subgroup's identity and cultural practices or uncertainty about its political-economic status. 
2 | IDENTITY-CENTRALITY IN

SUBGROUP-SUPERORDINATE GROUP RELATIONS

Superordinate groups can play a beneficial role in society. They can promote positive relations between conflicting subgroups and establish a common goal to focus on during interactions (Gaertner \& Dovidio, 2000; Sherif, 1958). They can also distribute resources to subgroups that might not be available elsewhere, such as economic opportunities and civil rights (Tyler, Degoey, \& Smith, 1996).

However, superordinate groups can have an opposite effect. Although superordinate groups have the laudable goal of promoting an integrated common identity that transcends subgroup differences, subgroups can see things differently. A superordinate identity can, according to social identity theory (e.g., Tajfel \& Turner, 1979), be viewed as a threat to people's distinct identity and normative practices provided by their subgroup (Brown \& Hewstone, 2005; Hogg, 2015; Hogg \& Hornsey, 2006; Hornsey \& Hogg, 2000).

Concern about subgroup-superordinate group identity dynamics is most pronounced among people who consider one of these social identities to be more central to their overall sense of who they are. People with highidentity-centralitycommonlydefinetheirself-conceptthroughaparticular social group, and perceive themselves as members of this group (Kachanoff, Ysseldyk, Taylor, Sablonniere, \& Crush, 2016). Identity-centrality differs from identity-salience, which is a situational activation of group membership (Stryker \& Serpe, 1994); and from in-group affect, which is an emotional attachment to one's in-group (Kachanoff et al., 2016). Thus, identity-centrality refers to the stable, self-definitional importance of a group, and its associated identity to an individual.

Because people define themselves as members of multiple social groups and categories, some with overlapping attributes (cf. Roccas $\&$ Brewer, 2002), the notion of identity-centrality may be better understood in terms of relative identity-centrality-people differentially weight the importance of groups and identities to their self-concept (Jung, Hogg, \& Lewis, 2018). Research shows that relatively stronger subgroup (vs. superordinate) identification predicts less endorsement of superordinate values and greater endorsement of subgroup values (Wan, Chiu, Peng, \& Tam, 2007). People with relatively stronger subgroup (compared to superordinate) identification also have lower levels of contact with other nested out-groups within the superordinate group (Cehajic, Brown, \& Castano, 2008). People overall identify with both their superordinate and subgroup, and the group that is more central to their self-concept will be weighted more heavily when making decisions and engaging in behaviors.

\section{3 | IDENTITY-UNCERTAINTY AND THE PURSUIT OF SUBGROUP AUTONOMY}

A key motivation for group identification and for considering a particular identity as central to self-definition is self-uncertainty reduction. According to uncertainty-identity theory (Hogg, 2007, 2012 ), feeling uncertain about one's self-concept can be disconcerting and maladaptive, and can arise when people feel uncertain about their group's identity, what their group stands for and what its future might be (e.g., Wagoner, Belavadi, \& Jung, 2017). People are motivated to reduce such uncertainty. This can be effectively achieved by identifying with a group, particularly an entitative group that has a distinct and clearly defined identity and set of normative practices (e.g., Hogg, Meehan, \& Farquharson, 2010).

As noted by the centrality proposition of uncertainty-identity theory (Jung et al., 2018), people are also more concerned and affected by the uncertainties that are central to their self and identity compared those uncertainties that are more distal and less central to self-conceptualization. Research confirms that uncertainty about a central (vs. peripheral) aspect of our self-concept elicits a stronger motivation to reduce its presence, and consequently stronger group identification (Mullin \& Hogg, 1999).

How does self-uncertainty reduction work in the context of nested subgroups and relative identity centrality? Given that people are members of both a nested subgroup and its broader superordinate group, they are motivated to reduce identity-uncertainty for the group most central to their self-concept. One response to subgroup identity-uncertainty is to identify more strongly at the superordinate level, or vice versa. Research confirms this hydraulic mechanism by showing people compensate their subgroup identity-uncertainty by strengthening their superordinate group identification (Jung, Hogg, \& Choi, 2016).

Importantly, this stronger subgroup identification can lead to the pursuit of subgroup autonomy, which is when people strive for their subgroup to have greater independence from the superordinate group in making decisions about their own norms, values, future and identity. Wagoner and Hogg (2016) found that when people compensated their superordinate identity-uncertainty by strengthening their subgroup identification, they expressed stronger support for subgroup autonomy. Support of subgroup autonomy involves pursuing a clear identity that is independent and distinct from the uncertainty associated with the superordinate group.

In sum, recent research on uncertainty-identity theory shows that (a) strengthening group identification with subjectively important groups can reduce uncertainty, (b) people can feel uncertainty about their self-concept and social groups, and (c) identity-uncertainty drives subgroup autonomy.

\section{I DIMENSIONS OF UNCERTAINTY IN MOTIVATING SUBGROUP AUTONOMY}

Although research has primarily focused on uncertainty about identity and cultural practices, there are various reasons why groups can experience uncertainty. For example, nations can collectively experience uncertainty about their economic future, universities can collectively experience uncertainty about funding, and natural disasters can produce uncertainty for entire regions of people. In these instances, it is not uncertainty about one's social identity, but instead a sense of 
what we have called politico-economic uncertainty where people feel uncertain about their resources, economic outlook, and socio-political climate.

These dimensions of group-based uncertainty differ in that politico-economic uncertainty is focused on feeling uncertain about possessing tangible resources and economic and political opportunities, while identity-uncertainty is focused on the symbolic nature of what the group stands for and what it means to be a group member. This distinction between economic and identity based attitudes reflects other social psychological literature focusing on group processes and intergroup relations (Riek, Mania, \& Gaertner, 2006). Although economists have investigated how uncertainty about the economy affects decision-making processes (Baker, Bloom, \& Davis, 2015), no research has investigated whether this type of politico-economic uncertainty produces similar effects as identity-uncertainty.

\section{5 | THE PRESENT STUDY}

To examine which type of group-based uncertainty motivates support for subgroup autonomy within a superordinate entity we focused on Sardinia as the subgroup within Italy as the superordinate group. Sardinia, because of its geographic location (an island in the Mediterranean Sea) and its history (different language and set of cultural practices), is one of the five Italian regions with special status, and since 1948 the Italian constitution has granted special conditions of autonomy to the region. The presence of several pro-independence political parties, from the beginning of the history of the Italian republic to this day, is a testament to Sardinia's long-desired independence from Italy (see: Brigaglia, Mastino, \& Ortu, 2002).

Although past research shows a hydraulic effect where people are more supportive of subgroup autonomy when they feel uncertain about their superordinate identity (Wagoner \& Hogg, 2016), other research shows that when subgroup identity is highly central to a person's self-concept people are motivated to defend their subgroups distinctiveness when it becomes ambiguous within the superordinate group (Crisp, Stone, \& Hall, 2006; Jetten, Spears \& Manstead, 2001). This defense-based response where people strive to clarify their subgroup's identity rather than compensate for its ambiguity may result from people highly valuing their subgroup identity more than their superordinate identity. Thus, it is possible that when a subgroup is self-conceptually central people are more sensitive to subgroup than superordinate identity-uncertainty-the former uncertainty is more subjectively impactful.

We further believe that people can experience relatively more (or less) uncertainty about their subgroup or their superordinate group, similar to how people can have relatively stronger subgroup or superordinate identity-centrality. Since relative identity-centrality weights the subjective importance of two groups against each other, it is possible that people also weight feelings of uncertainty about their subgroup and superordinate group against each other (i.e., relative uncertainty). From this perspective, people are more susceptible to feelings of uncertainty about the group that is more central to their self-concept.
Finally, another way subgroups could secure autonomy is if the broader, superordinate entity fragments and loses its ability to regulate its smaller factions. That is, people could obtain autonomy for their subgroup if the superordinate group that governs it fragments (i.e., superordinate fragmentation). This fragmentation of the superordinate group could allow subgroups to have independent decisionmaking over their own policies, norms, and future (i.e., subgroup autonomy), and thus have a clearer identity. Since previous research has not examined different dimensions of group-based uncertainties nor differentiated ways of pursuing subgroup autonomy, it remains unclear what dimension of uncertainty at what level of identity drives the pursuit of subgroup autonomy.

We measured superordinate and subgroup identity-centrality, along with identity-uncertainty and politico-economic uncertainty at both a superordinate and subgroup level, as our predictor variables. We measured support of subgroup autonomy and support of superordinate group fragmentation as our dependent variables. We hypothesized that when people's subgroup was more central to their self-concept they would be more supportive of subgroup autonomy $(\mathrm{H} 1 \mathrm{a})$ and of superordinate fragmentation $(\mathrm{H} 1 \mathrm{~b})$ when experiencing uncertainty about their subgroup identity (relative to their superordinate identity). We also hypothesized that it was uncertainty about a subgroup's identity, not uncertainty about its political or economic environment that was driving support for subgroup autonomy (H2a) and superordinate fragmentation $(\mathrm{H} 2 \mathrm{~b})$.

\section{6 | METHODS}

\section{1 | Participants and Design}

Participants were 76 males and 98 females $(N=174)$, all residents of Sardinia, with an average age of 48.54 (SD =9.84). They were recruited via social media sites and asked to complete an on-line survey about their attitudes toward Sardinia's and Italy's culture and economy. All participants completed measures of Sardinian and Italian identity-centrality before completing measures of identity-uncertainty and politico-economic uncertainty for both Sardinia and Italy. Participants then completed the two dependent variables-how much they supported Sardinia having autonomy over their policy-making decisions from Italy, and how much they supported Italy fragmenting into autonomous states. Demographic data (age, sex) were collected at the end of the study before participants were debriefed.

\subsection{Measure and Materials}

After consenting participants completed a seven-item measure of Italian identity-centrality: (1) "Overall, how important do you feel being Italian is to who you are"; (2) "Overall, how central do you feel being Italian is to who you are"; (3) "Overall, how of ten do you think of yourself as Italian"; (4) "How much do you feel you identify with Italy"; (5) "How proud do you feel to be an Italian"; (6) "How strong do you feel your ties are with fellow Italians"; and (7) "How much solidarity do you feel you have with Italians"; 1 not very much, 9 very much ( $M=5.95$, 


\begin{tabular}{llllll} 
Variables & M & SD & 1 & 2 & 3 \\
\hline 1. Relative identity-centrality & 1.34 & 2.46 & - & & \\
2. Relative identity-uncertainty & -1.23 & 2.33 & $-0.58^{* * *}$ & - & \\
$\begin{array}{l}\text { 3. Relative politico-economic } \\
\text { uncertainty }\end{array}$ & -0.35 & 1.18 & $-0.24^{* *}$ & $0.17^{*}$ & - \\
\hline
\end{tabular}

TABLE 1 Means, standard deviations, and correlations for relative variables

${ }^{*} p<0.05 .{ }^{* *} p<0.01 .{ }^{* * *} p<0.001$.

$S D=2.21, \alpha=0.94)$. Participants completed this same measure for Sardinian identity-centrality $(M=7.28, S D=1.88, \alpha=0.95)$. These questions were taken from previous research examining identity-centrality and group identification (Antonini, Hogg, Mannetti, Barbieri, \& Wagoner, 2015; Jung et al., 2016; Wagoner \& Hogg, 2016).

Participants then completed a four-item measure of Italian identity-uncertainty: (1) "How uncertain do you feel about what it means to be an Italian"; (2) "How uncertain do you feel about the characteristics that define being an Italian"; (3) "How uncertain do you feel about what Italy stands for"; and (4) "How uncertain do you feel about the distinctiveness of Italy's identity within the European Union"; 1 not very much, 9 very much $(M=4.66, S D=2.36, \alpha=0.91)$. Participants completed the same measure of identity-uncertainty for Sardinia $(M=3.42, S D=2.07, \alpha=0.89)$. These questions for both superordinate and subgroup identity-uncertainty were taken from a recently validated measure of identity-uncertainty (Wagoner et al., 2017).

Participants then completed a four-item measure of politico-economic uncertainty for Italy: (1) "How uncertain do you feel about Italy's current economic condition"; (2) "How uncertain do you feel about Italy's current political condition"; (3) "How uncertain do you feel about Italy's economic future"; and (4) "How uncertain do you feel about Italy's political future"; 1 not very much, 9 very much $(M=8.12$, $S D=1.09, \alpha=0.92$ ). Participants completed the same measure of politico-economic uncertainty for Sardinia $(M=7.76, S D=1.41, \alpha=0.92$ ). These questions were specially created for this study.

We measured support for Sardinian autonomy in two ways-directly and indirectly. Participants completed a six-item direct measure of support for subgroup autonomy. They were asked how much they support Sardinia having independence from Italy in regards to: (1) "governance"; (2) "economic policies"; (3) "social policies"; (4) "environmental policies"; (5) "cultural practices"; and (6) "immigration policies"; 1 not verymuch, 9 verymuch $(M=6.77, S D=2.14, \alpha=0.95)$. These questions were adapted from previous research examining subgroup autonomy (Wagoner \& Hogg, 2016).

To measure support for Sardinian autonomy indirectly, participants indicated their support of Italy fragmenting into autonomous states (i.e., superordinate fragmentation) on a four-item scale: (1) "How much do you support Italy dissolving into autonomous regions"; (2) "How much do you support the Italian government breaking apart into smaller governments"; (3) "How much do you support each region of Italy having a unique constitution"; and (4) "How much do you support each region of Italy having a distinct Governor"; 1 not very much, 9 verymuch $(M=4.64, S D=2.43, \alpha=0.86)$. These questions were created for the purposes of this study.
Participants lastly reported their age and sex. All measures were completed in Italian-they were translated from English using a standard back-translation method.

\section{7 | RESULTS}

\section{1 | Scale construction and demographics}

An exploratory factor analysis with oblimin rotation was performed on the 14-items measuring Sardinian and Italian identity centrality (seven-items each). Two distinct factors emerged to account for $71.86 \%$ of the variance. Factor 1 (Eigenvalue $=6.42$ ) accounted for $45.86 \%$ of the variance and had factor loadings above 0.60 on the seven Sardinian identity-centrality items. Factor 2 (Eigenvalue $=3.64$ ) accounted for $29.00 \%$ of the variance and had factor loadings above .60 on the seven Italian identity-centrality items.

We conducted another exploratory factor analysis with oblimin rotation on the 16-items measuring Sardinian and Italian identityuncertainty (four-items each) and Sardinian and Italian politico-economic uncertainty (four-items each). Four distinct factors emerged to account for $80.26 \%$ of the variance. Factor 1 (Eigenvalue $=6.51$ ) accounted for $40.70 \%$ of the variance and had factor loadings above 0.60 on the four Sardinian identity-uncertainty items. Factor 2 (Eigenvalue $=3.19$ ) accounted for $19.94 \%$ of the variance and had factor loadings above $\mathbf{0 . 6 0}$ on the four Italian identity-uncertainty items. Factor 3 (Eigenvalue $=1.88$ ) accounted for $11.73 \%$ of the variance, and had factor loadings above .60 on the four Sardinian politico-economic uncertainty items. Lastly, Factor 4 (Eigenvalue $=1.26$ ) accounted for $7.89 \%$ of the variance, and had factor loadings above 0.60 on the four Italian politico-economic uncertainty items.

To construct our measure of relative identification, we subtracted scores on our Italian identification scale from scores on our Sardinian identification scale. We followed this same process of subtracting Italian scores from Sardinian scores for creating measures of relative identity-uncertainty and relative politico-economic uncertainty. Across all relative scales higher scores indicate higher levels of Sardinian identity-centrality (or uncertainty)-See Table 1 for correlation matrix. This practice of constructing difference scores follows previous researchers who have compared relative strength of group identification (Brewer, 1991; Jung et al., 2017; Wan et al., 2007).

Following Aiken and West (1991), we centered our predictor variables (relative identity-centrality, relative identity-uncertainty, relative politico-economic uncertainty) before creating an interaction terms for relative identity-centrality $\times$ relative identity-uncertainty, 
and for relative identity-centrality $\times$ relative politico-economic uncertainty.

We examined whether our demographics were related to any of our predictors, interaction terms, or dependent variables. A series of bivariate correlations showed that age was related to weaker subgroup identity-centrality $(r=-0.25, p<0.001)$, and related to more subgroup identity-uncertainty $(r=0.16, p=0.04)$. Additionally, females had more Italian identity-centrality $(r=-0.19, p=0.01)$, and weaker support of superordinate fragmentation $(r=-0.34, p<0.01)$. Lastly, results showed that gender was related to the interaction between identity-centrality and identity-uncertainty $(r=0.16, p=0.02)$, and the interaction between identity-centrality and politico-economic uncertainty $(r=0.21, p=0.01)$. No other correlations were statistically significant ( $p s>0.16$ ). Because our demographics were related to our predictors, interaction terms and dependent variables, we controlled for them across our analyses.

\section{2 | Testing Relative Identity-Centrality and Dimensions of Uncertainty}

\subsection{1 | Subgroup autonomy}

We conducted a hierarchical linear regression with our demographics (age, sex) in Step 1, our centered predictor variables (relative identitycentrality, relative identity-uncertainty, relative politico-economic uncertainty) in Step 2, and our interaction terms (relative identitycentrality $\times$ relative identity-uncertainty, relative identity-centrality $\times$ relative politico-economic uncertainty) in Step 3 .

Step 1, which included our demographic variables, was non-significant, $R^{2}=0.01, F(2,171)=0.92, p=0.40$. Step 2 , which added our three predictor variables, accounted for a significantly amount of variance in subgroup autonomy support, $\Delta R^{2}=0.18, F(3,168)=12.54$, $p<0.001$. Results showed that relatively more subgroup identitycentrality predicted more support of subgroup autonomy, $\beta=0.47, t$ $(168)=5.13, p<0.001$. Neither relative identity-uncertainty nor relative politico-economic uncertainty predicted support of subgroup autonomy ( $p s>0.78$ )-See Table 2.

Step 3, which entered in our two interactions terms, was also statistically significant, $\Delta R^{2}=0.05, F(2,166)=5.38, p<0.01$. Results showed that more subgroup identity-centrality remained a significant predictor of subgroup autonomy support, $\beta=0.49, t(166)=5.50$, $p<0.001$. Importantly, and as predicted, the interaction between relative identity-centrality and relative identity-uncertainty on subgroup autonomy support was statistically significant, $\beta=0.19, t(166)=2.67$, $p<0.01$. The interaction between relative identity-centrality and relative politico-economic uncertainty did not significantly predict support of subgroup autonomy, $\beta=0.10, t(166)=1.48, p=0.14-$ See Table 2.

Analyses of simple slopes revealed that people with relatively stronger subgroup identity-centrality supported subgroup autonomy
TABLE 2 Hierarchical regression of main effects and interactions on subgroup autonomy

\begin{tabular}{|c|c|c|c|c|c|}
\hline Variable & $d f$ & $F$ & $R^{2} \Delta$ & $t$ & $\boldsymbol{\beta}$ \\
\hline Step 1 & 2,171 & 0.92 & 0.01 & & \\
\hline Age & & & & 0.07 & 0.01 \\
\hline Sex $(0=$ Male, $1=$ Female $)$ & & & & -1.35 & -0.11 \\
\hline Step 2 & 3,168 & $12.54^{* * *}$ & 0.18 & & \\
\hline Age & & & & 1.72 & 0.12 \\
\hline Sex $(0=$ Male, $1=$ Female $)$ & & & & -0.13 & -0.01 \\
\hline Relative identity-centrality & & & & $5.13^{* * *}$ & 0.47 \\
\hline $\begin{array}{l}\text { Relative } \\
\text { identity-uncertainty }\end{array}$ & & & & 0.27 & 0.02 \\
\hline $\begin{array}{l}\text { Relative politico-economic } \\
\text { uncertainty }\end{array}$ & & & & 0.17 & 0.01 \\
\hline Step 3 & 2,166 & $5.38^{* *}$ & 0.05 & & \\
\hline Age & & & & 1.55 & 0.10 \\
\hline Sex $(0=$ Male, $1=$ Female $)$ & & & & -0.81 & -0.06 \\
\hline Relative identity-centrality & & & & $5.49^{* * *}$ & 0.49 \\
\hline $\begin{array}{l}\text { Relative } \\
\text { identity-uncertainty }\end{array}$ & & & & 0.59 & 0.05 \\
\hline $\begin{array}{l}\text { Relative politico-economic } \\
\text { uncertainty }\end{array}$ & & & & 0.29 & 0.02 \\
\hline $\begin{array}{l}\text { Centrality } \times \text { identity-uncer- } \\
\text { tainty }\end{array}$ & & & & $2.87^{* *}$ & 0.19 \\
\hline $\begin{array}{l}\text { Centrality } \times \text { politico-eco- } \\
\text { nomic }\end{array}$ & & & & 1.48 & 0.10 \\
\hline
\end{tabular}


more strongly when they had high levels of superordinate identityuncertainty, $\beta=0.26, t(166)=3.50, p<0.001$. Results also showed, as predicted, that people with relatively stronger subgroup identity-centrality supported subgroup autonomy more strongly when they had high levels of subgroup identity-uncertainty, $\beta=0.42$, $t(166)=5.95, p<0.001-$ See Figure 1. A $z$-test showed that the relationship between relative identity-centrality and subgroup autonomy was stronger among people with high subgroup identity-uncertainty compared to high superordinate identity-uncertainty, $z=1.68, p$ (one-tailed) $=0.04$.

Results further showed that among people with high subgroup identity-centrality, relatively higher levels of subgroup identity-uncertainty predicted more support for subgroup autonomy, $\beta=0.14, t$ $(166)=1.85, p=0.06-$ See Figure 1. Relative identity-uncertainty did not predict support for subgroup autonomy for people with high levels of superordinate identity-centrality, $p=0.36$.

\subsection{2 | Superordinate fragmentation}

We conducted a hierarchical linear regression with our demographics in Step 1, our centered predictor variables (relative identity-centrality, relative identity-uncertainty, relative politico-economic uncertainty) in Step 2, and our interaction terms (relative identity-centrality $\times$ relative identity-uncertainty, relative identity-centrality $\times$ relative politico-economic uncertainty) in Step 3.

Step 1 showed that our demographic variables accounted for a significant amount of variance in superordinate fragmentation support, $R^{2}=0.13, F(2,171)=12.54, p<0.001$. Results showed that females had less support of Italy fragmenting into autonomous states than males, $\beta=-0.34, t(171)=-4.78, p<0.001$. Results also showed that younger people were marginally more supportive of superordinate fragmentation, $\beta=-0.12, t(171)=-1.71, p=0.09$.

Step 2, which added our three predictor variables, accounted for a significant amount of variance in superordinate fragmentation, $\Delta R^{2}=0.21, F(3,168)=17.28, p<0.001$. Females still had less support of superordinate fragmentation than males, $\beta=-0.26, t(168)=-4.00$, $p<0.001$. But importantly, results revealed that relatively stronger

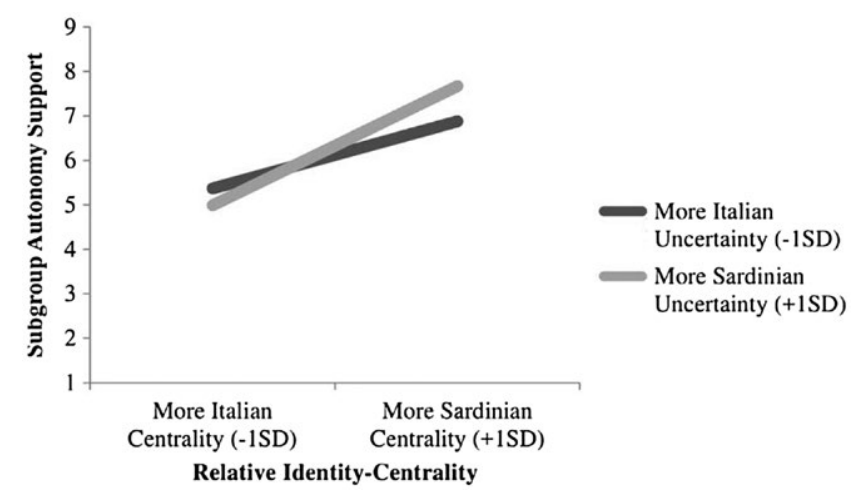

FIGURE 1 Two-way interaction between relative identitycentrality and relative identity-uncertainty on support of subgroup autonomy subgroup identity-centrality predicted more support of regions having autonomy within Italy, $\beta=0.39, t(168)=4.85, p<0.001-$ See Table 2. Neither relative identity-uncertainty nor relative politicoeconomic uncertainty predicted support of superordinate fragmentation ( $p s>0.17$ ).

Finally, adding our two interactions terms (identity-centrality $\times$ identity-uncertainty,identity-centrality $\times$ politico-economicuncertainty) into Step 3 did not account for significantly more variance in support of superordinate fragmentation, $\Delta R^{2}=0.01, F(2,166)=1.82$, $p=0.17-$ See Table 3 .

\section{8 | DISCUSSION}

Subgroups are tied to their superordinate groups through a common identity and a shared history. However, subgroups also have a distinct and cherished identity that their members wish to preserve in the context of their superordinate group, especially when their subgroup is more psychologically central to their self-concept. In the present article we focus on the dynamic relationship between subgroup's and their superordinate group and asked (a) which types of uncertainty motivate subgroups to seek autonomy, and (b) how does the psychological centrality of group membership affects this drive for autonomy?

Drawing upon uncertainty-identity theory (Hogg, 2007, 2012 ), which theorizes that uncertainty can be resolved by strengthening group identification, we examined how the self-conceptual centrality of group membership and the nature of the uncertainty would affect support for subgroup autonomy. We hypothesized that uncertainty about one's subgroup identity, not its politico-economic environment, would generate greater support for subgroup autonomy, and supporting for having autonomous states in their superordinate group. Moreover, we believed this tendency would be exacerbated among people whose subgroup was more central than their superordinate group to their self-concept (i.e., relative-identity centrality).

We explored these ideas in the context of Sardinia as a distinct region (subgroup) within Italy (superordinate group). We measured Sardinians' ratings of Sardinia and Italy in terms of identity centrality, identity-uncertainty and politico-economic uncertainty before measuring their support for Sardinian autonomy and for Italy fragmenting into autonomous states.

Results showed that people with stronger subgroup (relative to superordinate group) identity-centrality had more support of Sardinian autonomy. But as predicted, higher levels of subgroup identity-centrality predicted stronger pursuit of subgroup autonomy when experiencing uncertainty about their subgroup's identity $(\mathrm{H} 1 \mathrm{a})$, and not about its political or economic climate ( $\mathrm{H} 2 \mathrm{a})$. Furthermore, Sardinians with stronger subgroup identity-centrality had more support of Italy fragmenting into autonomous states, which relates to support of subgroup autonomy; however, neither relative identity-uncertainty nor relatively politico-economic uncertainty predicted Sardinian's support of Italy fragmenting into autonomous states ( $\mathrm{H} 2 \mathrm{a}, \mathrm{b})$. 


\begin{tabular}{|c|c|c|c|c|c|}
\hline Variable & $d f$ & $F$ & $R^{2} \Delta$ & $t$ & $\beta$ \\
\hline Step 1 & 2,171 & $12.54^{* * *}$ & 0.13 & & \\
\hline Age & & & & -1.71 & -0.12 \\
\hline Sex $(0=$ Male, $1=$ Female $)$ & & & & $-4.78^{* * *}$ & -0.34 \\
\hline Step 2 & 3,168 & $17.28^{* * *}$ & 0.21 & & \\
\hline Age & & & & 0.01 & 0.00 \\
\hline Sex $(0=$ Male, $1=$ Female $)$ & & & & $-4.00^{* *}$ & -0.26 \\
\hline Relative identity-centrality & & & & $4.72^{* * *}$ & 0.39 \\
\hline $\begin{array}{l}\text { Relative } \\
\text { identity-uncertainty }\end{array}$ & & & & -1.38 & -0.11 \\
\hline $\begin{array}{l}\text { Relative politico-economic } \\
\text { uncertainty }\end{array}$ & & & & -0.83 & -0.05 \\
\hline Step 3 & 2,166 & 1.82 & 0.01 & & \\
\hline Age & & & & -0.11 & -0.01 \\
\hline Sex $(0=$ Male, 1 = Female $)$ & & & & $-4.31^{* *}$ & -0.29 \\
\hline Relative identity-centrality & & & & $4.87^{* * *}$ & 0.40 \\
\hline $\begin{array}{l}\text { Relative } \\
\text { identity-uncertainty }\end{array}$ & & & & -1.20 & -0.09 \\
\hline $\begin{array}{l}\text { Relative politico-economic } \\
\text { uncertainty }\end{array}$ & & & & -0.75 & -0.05 \\
\hline $\begin{array}{l}\text { Centrality } \times \text { identity-uncer- } \\
\text { tainty }\end{array}$ & & & & 1.60 & 0.10 \\
\hline $\begin{array}{l}\text { Centrality } \times \text { politico-eco- } \\
\text { nomic }\end{array}$ & & & & 0.78 & 0.05 \\
\hline
\end{tabular}

TABLE 3 Hierarchical regression of main effects and interactions on superordinate group fragmentation

${ }^{* *} p<0.01 .{ }^{* * *} p<0.001$.

In sum, we believe these results support our theorizing that an identity-based tension affects a subgroup's relationship with their superordinate group by producing uncertainty about the subgroup's identity, which elicits a pursuit of autonomy. Although we believe this pursuit of autonomy is to secure a clear and coherent identity, we did not actually investigate whether obtaining subgroup autonomy would clarify the group's identity and weaken feelings of identity-uncertainty. Researchers should investigate whether actually obtaining autonomy from a superordinate entity psychologically benefits (or harms) the individual and their identity.

These results also suggest that identity-based dynamics of the subgroup-superordinate relationship may affect support for superordinate fragmentation. Although stronger subgroup identitycentrality predicted more support for fragmentation, our research suggests neither identity-uncertainty nor politico-economic uncertainty is driving this support for fragmentation. Since our theorizing is based on the proposition that identity-uncertainty engages mechanisms aimed at establishing a clear identity for groups that are central to our self, perhaps fragmenting a superordinate group would not help clarify one's nested subgroup identity, even if providing it autonomy.

It is also possible that this measure of superordinate fragmentation assessed people's attitudes towards regions in Italy having greater autonomy, not support of Italy completely fragmenting and ceasing to exist. Because we reasoned that superordinate fragmentation is an indirect path toward subgroup autonomy, future research should distinguish the psychological mechanisms that lead to support for actual fragmentation of the superordinate group compared to support for one's subgroup purely seeking autonomy.

Finally, we believe these results can be applied to other countries within the European Union that have growing independence movements (e.g., Catalonia, Italy, the Netherlands) or have supported dissolving the European Union (Pasha-Robinson, ). Although these movements are focusing on exiting or fragmenting the European Union, we believe at the heart of these movements is a drive for autonomy over the direction of one's subgroup and its identity. Given this proposition, perhaps the leaders of governmental institutions should focus more on validating subgroup's identity within their superordinate group instead of focusing on the available economic opportunities.

\section{ACKNOWLEDGMENTS}

We would like to thank the Social Identity Lab at Claremont Graduate University for their helpful feedback on this project.

\section{ORCID}

Joseph A. Wagoner (iD http://orcid.org/0000-0002-2549-521X 


\section{REFERENCES}

Aiken, L. S., \& West, S. G. (1991). Multiple regression: Testing and interpreting interactions. Thousand Oaks, CA: Sage.

Antonini, M., Hogg, M. A., Mannetti, L., Barbieri, B., \& Wagoner, J. A. (2015). Motivating citizens to participate in public policy making: Identification, trust, and cost-benefit analysis. Journal of Social and Political Psychology, 3, 131-147. https://doi.org/10.5964/jspp. v3i2.408

Baker, S. R., Bloom, N., \& Davis, S. J. (2015). Measuring economic policy uncertainty. The Quarterly Journal of Economics, 131, 1593-1636. https://doi.org/10.1093/qje/qjw024

Brewer, M. B. (1991). The social self: On being the same and different at the same time. Personality and Social Psychology Bulletin, 17, 475482. https://doi.org/10.1177/0146167291175001

Brigaglia, M., Mastino, A., \& Ortu, G. G. (2002). Storia della Sardegna. 5: II Novecento. Rome-Bari: Editori Laterza.

Brown, R. J., \& Hewstone, M. (2005). An integrative theory of intergroup contact. Advances in Experimental Social Psychology, 37, 255-343. https://doi.org/10.1016/S0065-2601(05)37005-5

Cehajic, S., Brown, R., \& Castano, E. (2008). Forgive and forget? Antecedents and consequences of intergroup forgiveness in Bosnia and Herzegovina. Political Psychology, 29, 351-367. https://doi. org/10.1111/jasp.12549

Crisp, R. J., Stone, C. H., \& Hall, N. R. (2006). Recategorization and subgroup identification: Predicting and preventing threats from common ingroups. Personality and Social Psychology Bulletin., 32, 230-243. https://doi.org/10.1177/0146167205280908

Gaertner, S. L., \& Dovidio, J. F. (2000). Reducing intergroup bias: The common ingroup identity model. New York: Psychology Press.

Hogg, M. A. (2007). Uncertainty-identity theory. Advances in Experimental Social Psychology, 39, 69-126. https://doi.org/10.1016/ s0065-2601(06)39002-8

Hogg, M. A. (2012). Uncertainty-identity theory. In P. A. M. Van Lange, A. W. Kruglanski, \& E. T. Higgins (Eds.), Handbook of theories of social psychology, Vol. 2 (pp. 62-80). Thousand Oaks, CA: Sage.

Hogg, M. A. (2015). Constructive leadership across groups: How leaders can combat prejudice and conflict between subgroups. Advances in Group Processes, 32, 177-207. https://doi.org/10.1108/ S0882-614520150000032007

Hogg, M. A., \& Hornsey, M. J. (2006). Self-concept threat and multiple categorization with groups. In R. J. Crisp, \& M. Hewstone (Eds.), Multiple social categorization: Processes, models, and applications. New York: Psychology Press.

Hogg, M. A., Meehan, C., \& Farquharson, J. (2010). The solace of radicalism: Self-uncertainty and group identification in the face of threat. Journal of Experimental Social Psychology, 46, 1061-1066. https:// doi.org/10.1016/j.jesp.2010.05.005

Hornsey, M. J., \& Hogg, M. A. (2000). Assimilation and diversity: An integrative model of subgroup relations. Personality and Social Psychology Review, 4, 143-156. https://doi.org/10.1207/ S15327957PSPR0402_03

Jetten, J., Spears, R., \& Manstead, A. S. R. (2001). Similarity as a source of differentiation: The role of group identification. European Journal of Social Psychology, 31, 621-640. https://doi.org/10.1002/ejsp.72

Jung, J., Hogg, M. A., \& Choi, H.-S. (2016). Reaching across the DMZ: Identity uncertainty and reunification of the Korean Peninsula. Political Psychology, 37, 341-350. https://doi.org/10.1111/ pops.12252

Jung, J., Hogg, M. A., \& Lewis, G. J. (2018). Identity-centrality and UK-Scottish relations: Different dynamics depending on relative identity centrality. Group Processes \& Intergroup Relations, https:// doi.org/10.1177/1368430216678329

Kachanoff, F. J., Ysseldyk, R., Taylor, D. M., de la Sablonniére, R., \& Crush, J. (2016). The good, the bad, and the central of group identification: Evidence of a U-shaped quadratic relation between in-group affect and identity centrality. European Journal of Social Psychology, 46, 563-580. https://doi.org/10.1002/ejsp.2199

Mullin, B.-A., \& Hogg, M. A. (1999). Motivations for group membership: The role of subjective importance and uncertainty reduction. Basic and Applied Social Psychology, 21, 91-102. https://doi.org/10.1207/ S15324834BA210202

Pasha-Robinson, L. (2016, December 5). Italy referendum: Is the EU going to fall apart before Britain gets a chance to leave it? Retrieved from http://www.independent.co.uk/news/world/europe/italyreferendum-explained-eu-stability-brexit-uk-will-there-still-be-aunion-to-leave-a7456231.html

Riek, B. M., Mania, E. W., \& Gaertner, S. L. (2006). Intergroup threat and outgroup attitudes: A meta-analytic review. Personality and Social Psychology Review, 10, 336-353. https://doi.org/10.1207/ s15327957pspr1004_4

Roccas, S., \& Brewer, M. B. (2002). Social identity complexity. Personality and Social Psychology Review, 6, 88-106. https://doi.org/10.1207/ s15327957pspr0602_01

Sherif, M. (1958). Superordinate goals in the reduction of intergroup conflict. American Journal of Sociology, 63, 349-356. https://doi. org/10.1086/222258

Stryker, S., \& Serpe, R. T. (1994). Identity salience and psychological centrality: Equivalent, overlapping, or complementary concepts? Social Psychology Quarterly, 57, 16-35.

Tajfel, H., \& Turner, J. C. (1979). An integrative theory of intergroup conflict. In W. G. Austin, \& S. Worchel (Eds.), The social psychology of intergroup relations (pp. 33-47). Monterey, CA: Brooks/Cole.

Tyler, T. R., Degoey, P., \& Smith, H. (1996). Understanding why the justice of group procedures matter: A test of the psychological dynamics of the group value model. Journal of Personality and Social Psychology, 70, 913-930. https://doi.org/10.1037/0022-3514.70.5.913

Wagoner, J. A., Belavadi, S., \& Jung, J. (2017). Social identity uncertainty: Conceptualization, measurement, and construct validity. Self and Identity, 16, 505-530. https://doi.org/10.1080/15298868.2016.1 275762

Wagoner, J. A., \& Hogg, M. A. (2016). Normative dissensus, identityuncertainty, and subgroup autonomy. Group Dynamics: Theory, Research, and Practice, 20, 310-322. https://doi.org/10.1037/ gdn0000057

Wan, C., Chiu, C.-Y., Peng, S., \& Tam, K.-P. (2007). Measuring cultures through intersubjective cultural norms: Implications for predicting relative identification with two or more cultures. Journal of Cross-Cultural Psychology, 38, 213-226. https://doi. org/10.1177/0022022106297300

How to cite this article: Wagoner JA, Antonini M, Hogg MA, Barbieri B, Talamo A. Identity-centrality, dimensions of uncertainty, and pursuit of subgroup autonomy: The case of Sardinia within Italy. J Appl Soc Psychol. 2018;00:1-8. https:// doi.org/10.1111/jasp.12549 